Document downloaded from:

http://hdl.handle.net/10251/47608

This paper must be cited as:

Vallés Lluch, A.; Arnal Pastor, MP.; Martínez Ramos, C.; Vilariño Feltrer, G.; Vikingsson, L.; Castells Sala, C.; Semino, CE.... (2013). Combining self-assembling peptide gels with three-dimensional elastomer scaffolds. Acta Biomaterialia. 9(12):9451-9460. doi:10.1016/j.actbio.2013.07.038.

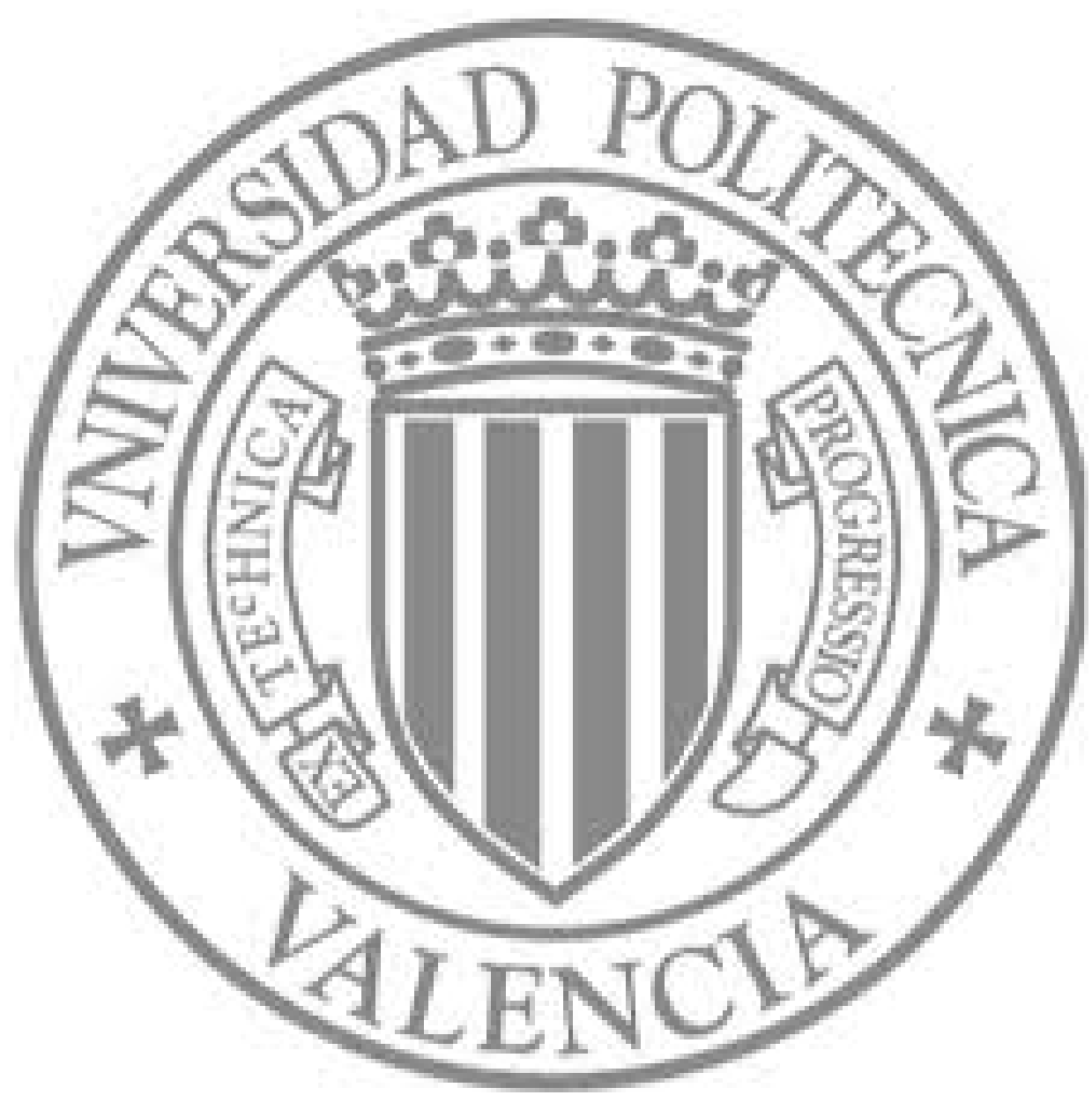

The final publication is available at

http://dx.doi.org/10.1016/j.actbio.2013.07.038

Copyright Elsevier 


\section{Elsevier Editorial System(tm) for Acta Biomaterialia}

Manuscript Draft

Manuscript Number: AB-13-384R2

Title: COMBINING SELF-ASSEMBLING PEPTIDE GELS WITH 3D ELASTOMER SCAFFOLDS

Article Type: Full Length Article

Keywords: scaffold; poly(ethyl acrylate); self-assembling peptide gel; controlled release; cell seeding

Corresponding Author: Prof. Manuel Monleón Pradas, PhD

Corresponding Author's Institution: Universidad Politécnica de Valencia

First Author: Ana Vallés Lluch, Ph.D.

Order of Authors: Ana Vallés Lluch, Ph.D.; María Arnal-Pastor, MSc; Cristina Martínez-Ramos, PhD; Guillermo Vilariño-Feltrer, MSc; Line Vikingsson, MSc; Cristina Castells-Sala, Msc; Carlos Eduardo Semino, PhD; Manuel Monleón Pradas, PhD

Abstract: Some of the problems raised by the combination of porous scaffolds and self-assembling peptide (SAP) gels as constructs for tissue engineering applications are for the first time addressed. Scaffolds of poly(ethyl acrylate) and the SAP gel RAD16-I were employed. The in situ gelation of the SAP gel inside the pores of the scaffolds was studied. The scaffold-cum-gel constructs were characterized morphologically, physico-chemically and mechanically. The possibility of incorporating an active molecule (bovine serum albumin, taken here as a model molecule for others) in the gel within the scaffold's pores was assessed, and the kinetics of its release in PBS was followed. Cell seeding and colonization of these constructs was preliminary studied with L929 fibroblasts and checked afterwards with sheep adipose-tissue derived stem cells (ASCs) intended for further preclinical studies. Static (conventional) and dynamically assisted seedings were compared for bare scaffolds and the scaffoldcum-gel constructs. The SAP gel inside the pores of the scaffold significantly improved the uniformity and density of cell colonization of the 3D structure. These constructs could be of use in different advanced tissue engineering applications where, apart from a cell-friendly ECM-like aqueous environment, a larger-scale three-dimensional structure able to keep the cells in a specific place, give mechanical support and/or conduct spatially the tissue growth could be required. 


\title{
COMBINING SELF-ASSEMBLING PEPTIDE GELS WITH 3D ELASTOMER SCAFFOLDS
}

A. Vallés-Lluch ${ }^{1}$, M. Arnal-Pastor ${ }^{*}$, C. Martínez-Ramos ${ }^{1 *}$, G. Vilariño-Feltrer ${ }^{1}$, L. Vikingsson $^{1}$, C. Castells-Sala ${ }^{2}$, C.E. Semino ${ }^{2}$, M. Monleón Pradas ${ }^{1,3, * *}$

${ }^{1}$ Center for Biomaterials and Tissue Engineering, Universitat Politècnica de València, Cno. de Vera s/n, 46022, Valencia, Spain

${ }^{2}$ Departament de Bioenginyeria IQS, Universitat Ramon Llull, Via Augusta 390, E08017 Barcelona, Spain

${ }^{3}$ Networking Research Center on Bioengineering, Biomaterials and Nanomedicine (CIBER-BBN), Spain

*Equal contribution

**Corresponding author. Tel.: +34963877277; fax: +34963877276. E-mail: mmonleon@ter.upv.es

\begin{abstract}
Some of the problems raised by the combination of porous scaffolds and selfassembling peptide (SAP) gels as constructs for tissue engineering applications are for the first time addressed. Scaffolds of poly(ethyl acrylate) and the SAP gel RAD16-I were employed. The in situ gelation of the SAP gel inside the pores of the scaffolds was studied. The scaffold-cum-gel constructs were characterized morphologically, physicochemically and mechanically. The possibility of incorporating an active molecule (bovine serum albumin, taken here as a model molecule for others) in the gel within the scaffold's pores was assessed, and the kinetics of its release in PBS was followed. Cell
\end{abstract}


seeding and colonization of these constructs was preliminary studied with L929 fibroblasts and checked afterwards with sheep adipose-tissue derived stem cells (ASCs) intended for further preclinical studies. Static (conventional) and dynamically assisted seedings were compared for bare scaffolds and the scaffold-cum-gel constructs. The SAP gel inside the pores of the scaffold significantly improved the uniformity and density of cell colonization of the 3D structure. These constructs could be of use in different advanced tissue engineering applications where, apart from a cell-friendly ECM-like aqueous environment, a larger-scale three-dimensional structure able to keep the cells in a specific place, give mechanical support and/or conduct spatially the tissue growth could be required.

Keywords: scaffold, poly(ethyl acrylate), self-assembling peptide gel, controlled release, cell seeding 


\section{Introduction}

Regenerative purposes impose multiple requirements to the material constructs intended to help those aims. In cardiac tissue engineering, for instance, the material vehicle for an efficient cell supply should ideally, among other things, host a large number of cells, guarantee their viability in situ, allow a rapid vascularization, and maybe give mechanical support to the infarcted myocardial tissue; this last requirement, in the case of neural tissue engineering, must be replaced by the appropriate guidance of axonal growth. It would be unlikely that the multifunctionality demanded for tissue engineering constructs by these applications could be achieved by simple, one-component material structures. Here we explore to which extent the combination of two different materials imparts to the resulting construct definite advantages from a tissue engineering point of view.

Synthetic or natural hydrogels possess many properties similar to those of the extracellular matrix (ECM), which makes them good candidates for engineered cellular niches. However, these gels cannot meet demanding mechanical requirements, which limit greatly their uses. Mechanical strength and geometrical definiteness should be provided by porous scaffolds. In a previous work [1] we studied how to incorporate a hyaluronic acid hydrogel into the porous structure of poly(ethyl acrylate) (PEA) elastomer scaffolds. Problems related to the filling technique, to the in situ crosslinking of the gel, and to the degree of pore coating or filling depending on the gel concentration, had to be addressed there. Other scaffolds with internal gel coating, such as the couples chitosan/fibrin [2], or polylactide/HA [3], have been studied; in each case, the filling and the gelation or crosslinking inside the pores represented specific difficulties to overcome. In the present paper we study constructs consisting of PEA 
scaffolds with the self-assembling peptide (SAP) RAD16-I hydrogel filling the pores. Some general questions raised by the combination of these very different materials are addressed here. How should the scaffold be filled? Can the peptide solution within the pores be gelled in situ? How should the cells be incorporated into the scaffold? Will the cells diffuse through the SAP lodged previously in the scaffold? Does indeed the construct show better biological performance than the empty scaffold?

Self-assembling peptide (SAP) hydrogels are a family of promising synthetic materials. They are injectable in aqueous solution and undergo spontaneous assembling into ordered nanostructures [4,5]. In this work, the RAD16-I peptide (commercially available as $\mathrm{BD}^{\mathrm{TM}}$ PuraMatrix ${ }^{\mathrm{TM}}$ ) has been used; it consists of a sequence of 16 aminoacids $\mathrm{AcN}-(\mathrm{RADA})_{4}-\mathrm{CONH}_{2}$ (R: arginine, A: alanine and $\mathrm{D}$ : aspartic acid), which forms $\beta$-sheet nanofiber-like gels as a response to $\mathrm{pH}$ or ion concentration changes [4,6-,9]. In vitro it encourages the adhesion of endothelial cells, their proliferation and formation of capillaries $[10,11]$ to enhance cardiac myocyte survival [12], and to support the survival, differentiation capacity and migration of neural stem cells [13] and the formation of synapses [14]. In mice, when injected with cardiac progenitors, it promotes angiogenesis and differentiation into cardiomyocytes and vascular smooth muscle cells [15]. Furthermore, as a wholly synthetic ECM-like medium, it presents the advantages, over other protein gels, of being easily functionalizable and of being free from pathogenicity worries. However, this SAP gel is but a little more consistent than an acqueous solution [16]; it does not meet the demands of shape stability and mechanical resistance of many tissue engineering applications. Thence the interest of its possible combination with other structurally more consistent materials. In [17] a RAD16-I solution containing Schwann cells was employed to fill 
the lumen of $2.2 \mathrm{~mm}$-diameter cellulose channels, to study regeneration across $10 \mathrm{~mm}$ gaps after peripheral nerve injury.

PEA is, at body temperature, a rubber when cross-linked, and its mechanical properties (elastic and loss moduli) have values not dissimilar to those of soft biological tissues. It has shown excellent compatibility with different types of cells in vitro: chondrocytes [18], keratinocytes [19], endothelial cells [20], neural cells [21-24], osteoblasts [25] or dental pulp stem cells [26], and has been recently proposed as a feeder-free platform for the maintenance and growth of human embryonic stem cells [27]. Due to its easy way of polymerization, PEA can be prepared in the form of scaffolds with different architectures, liable to invasion by cells and intended as guiding support for cell growth $[1,19,20,22,23,28-31]$.

Here we establish a protocol for the assembly of the RAD16-I peptide gel within the pores, having diameters smaller than a hundred microns, of hydrophobic PEA scaffolds, and characterize the performance of the combination as delivery platforms and as cell growth niches. The present is, up to our knowledge, the first work that studies such system hydrophobic scaffold plus RAD16-I hydrogel as in situ assembling filler of the micropores. Though these constructs are intended for future tissue engineering applications, the first studies here presented, due to their preliminary methodological nature, were performed using a commercial line of mouse fibroblasts; they have served to choose the main assembly conditions and to understand the role of the gel as a cell diffusion and encapsulation medium. The system here presented with ASCs is currently being employed in animal experiments as cell carrier to support the regeneration of cardiac tissue after myocardial infarction. In the present paper we characterize the assembly and cell seeding of these constructs. 


\section{Materials and methods}

\subsection{Preparation of the bare elastomer scaffolds}

Poly(ethyl acrylate) scaffolds with interconnected spherical pores were obtained by a radical polymerization of the monomer mixture and a template leaching technique, following a procedure analogous to that used in [29]. Briefly, ethyl acrylate (99\%, Aldrich) monomer was mixed with $1 \mathrm{wt} \%$ of benzoin (98\%, Scharlau) as photo-initiator and $2 \mathrm{wt} \%$ of ethyleneglycol dimethacrylate (98\%, Aldrich) as cross-linker, stirred for $15 \mathrm{~min}$, injected in the corresponding porogen template, polymerized for $24 \mathrm{~h}$ under a UV source, and post-polymerized for $24 \mathrm{~h}$ more in an oven at $90^{\circ} \mathrm{C} .5 \times 5 \mathrm{~cm}^{2}$ templates were previously obtained by sintering poly(methyl methacrylate) microspheres of $90 \pm$ $10 \mu \mathrm{m}$ in diameter (PMMA; Colacryl dp 300). After polymerization, the PMMA templates were removed by soxhlet extraction with acetone (Scharlab). After this, the solvent was slowly exchanged with water, and the scaffolds were dried under vacuum and stored until use. Their final thickness was $0.8 \mathrm{~mm}$ approximately.

Bulk $0.8 \mathrm{~mm}$-thick PEA sheets (hereafter 2DPEA) were synthesized by an analogous procedure, to be used as two-dimensional controls. The monomeric mixture was allowed to polymerize in a mold consisting of two glass plates with a rubber separator in between. Once polymerized, the sheets were rinsed in boiling acetone for $48 \mathrm{~h}$ with a solvent renewal and finally dried.

Samples for the different experiments were cut from the scaffolds or the bulk sheets as 8 mm-diameter circles. Bulk samples were employed to determine the water contact angle and swelling of the PEA matrix, because in its porous format the pores would interfere with such measurements. 


\subsection{Preparation of the scaffold-cum-gel constructs}

The SAP hydrogel RAD16-I (PuraMatrix ${ }^{\mathrm{TM}}$ 1\%(w/v), BD Biosciences) was used as a filler of the scaffolds' pores. In order to decrease the viscosity of the stock solution, the original package of RAD16-I was placed in a bath sonicator (Bandelin) for $30 \mathrm{~min}$ at $25^{\circ} \mathrm{C}$ and $30 \mathrm{~W}$ were applied. The stock solution was then diluted with water (extra pure, Scharlau) to a ready-to-use $0.15 \%(w / v)$ concentration (high enough to reach percolation of its network) one and vortexed (Elmi SkyLine) to ensure homogeneization. In order to facilitate the penetration of the still viscous SAP solution into the micropores of the hydrophobic PEA scaffolds, three different procedures were followed. The first method involved the incorporation of the peptide solution, loaded in a syringe, into the scaffolds by applying some pressure. The second method consisted in improving the wettability of the PEA scaffolds by a plasma treatment, and afterwards soaking them with the peptide solution. A Plasma-Electronic Piccolo chamber was employed, evacuated to $4 \cdot 10^{-2}$ mbar before generation of $\mathrm{Ar} / \mathrm{O}_{2}(1: 1)$ plasma at $25 \mathrm{~W}$ for $5 \mathrm{~min}$. The third filling procedure consisted in the introduction of the scaffolds, together with the SAP solution, in a tube closed with a septum rubber stopper, pierced by a syringe's needle, and the application of vacuum performing successive movements of the piston.

Once filled with the peptide solution, the scaffolds were placed in a Petri dish and drops of phosphate buffered saline (PBS) solution or culture medium were added to their boundaries to induce the self-assembly of the peptides. The SAP was allowed to gel in the pores of the scaffolds for 30 or $60 \mathrm{~min}$, which are the limits of the time range recommended by the manufacturer to obtain free gels. The obtained constructs were used for measurements immediately to avoid drying. Bare PEA scaffolds were kept as controls. 


\subsection{Morphology of the scaffold-cum-gel constructs}

Bare scaffold samples were examined by scanning electron microscopy (SEM) in a JSM 6300 (JEOL Ltd., Tokyo, Japan) device, with the samples previously sputter-coated with gold, $15 \mathrm{kV}$ of acceleration voltage and $15 \mathrm{~mm}$ of working distance. The samples were fractured in liquid nitrogen in order to obtain images of the surface and the crosssections.

The effective average pore diameter was determined with the free ImageJ software (National Institute of Mental Health, Bethesda, Maryland, USA) from 3 cross-section images at 200X. A set of pores were chosen and outlined, and the circularity of each one was calculated. The average pore diameter was obtained from the areas of 30 pores having circularities above $90 \%$.

The effectiveness of the filling procedure and the in situ gelation of the SAP once inside the scaffold's pores was assessed by cryoSEM in a JSM5410 (JEOL Ltd., Tokyo, Japan) instrument equipped with a cryounit (Oxford CT 1500). The samples were fixed vertically in a metal sample holder and submerged in liquid nitrogen to cut off a cross section and observe it. Water entrapped by the SAP before and after gelation was sublimated at $-70^{\circ} \mathrm{C}$ in the cryogenic unit for $15 \mathrm{~min}$ in vacuum so that the structure it left in the pores could be observed. Then, the samples were gold-sputtered and observed at $15 \mathrm{kV}$ and $15 \mathrm{~mm}$ of working distance. PBS injected in the pores following the procedure described above was employed as filling control for cryoSEM.

In parallel, the effective gelation (with PBS) of the SAP within the pores of the scaffolds was assessed by staining with a Congo red $0.1 \%(\mathrm{w} / \mathrm{v})$ acqueous solution (Fischer Scientific) for $20 \mathrm{~min}$ followed by $30 \mathrm{~min}$ of rinsing with water and macroscopical observation. Scaffolds with only PBS in their pores were also stained as controls. 


\subsection{Porosity determination}

The pore volume fraction of the bare scaffolds was obtained with the help of the density of PEA $\left(1.13 \mathrm{~g} / \mathrm{cm}^{3}\right.$ [29]), and the weight and apparent volume of the scaffolds, by triplicate. The porosity, $\pi$, is defined as the pore volume fraction of the scaffolds:

$$
\pi=\frac{V^{\text {pores }}}{V^{a p p}}=1-\frac{m v}{V^{a p p}}
$$

where $V^{\text {pores }}$ is the volume of pores, $V^{a p p}$ is the geometric (or apparent) volume, calculated from the measured linear dimensions of the scaffold, $m$ its weight and $v$ the PEA specific volume (reciprocal of its density). A Mettler AE 240 balance (MettlerToledo Inc., Columbus, OH, USA), with a sensitivity of $0.01 \mathrm{mg}$, was employed for this purpose. These tests were also carried out on scaffolds filled with SAPs to confirm the complete filling of the pores.

\subsection{Contact angle and swelling}

The PEA wettability was determined by measuring the average contact angle of extra pure water drops on the surface of 7 samples of 2DPEA in a Dataphysics OCA instrument (DataPhysics Instruments GmbH, Filderstadt, Germany).

To evaluate the PEA swelling, four $50 \mathrm{~mm}^{2}$ pieces of 2DPEA sheets were weighed vacuum dried and after different times of immersion in $\mathrm{PBS}$ at $37^{\circ} \mathrm{C}$ until equilibrium was confirmed, using the previously mentioned balance. The equilibrium water content, $E W C$, is defined as the ratio of the mass of absorbed water at equilibrium to the mass of dry material.

\subsection{Mechanical properties}


Mechanical compression tests were performed on cylindrical scaffolds having a diameter of $8 \mathrm{~mm}$, bare, filled with water and with the SAP gel, 5 replicas in each case. An EXSTAR TMA/ss6000 equipment (Seiko Instruments Inc., Chiba, Japan) was used for this purpose, the load increasing from 0 to $150 \mathrm{~g}$ at $10 \mathrm{~g} / \mathrm{min}$, at room temperature. Before measurements, the excess of SAP solution on the external surface of the scaffolds was carefully removed with a spatula. Measurements on empty scaffolds and on scaffolds filled with water were carried out as references. The compressive elastic moduli were obtained as the slope of the stress-strain plots in the linear deformation regions, at low deformations $\left(E_{1}\right)$ and at strain $0.3\left(E_{2}\right)$.

\subsection{BSA uptake and release from the scaffold-cum-gel construct}

The SAP solution was included within the pores of three pieces of PEA scaffolds of 8 $\mathrm{mm}$ of diameter, and gelled with PBS drops during $30 \mathrm{~min}$, as described. The scaffolds were weighed bare and after being filled with the gel to obtain the total amount of SAPs able to absorb the protein, $m^{g e l}$, as the difference. Bovine serum albumin (BSA; $2 \mathrm{mg} / \mathrm{ml}$ in $0.9 \%$ acqueous solution, Thermo Scientific) solution at a concentration, [BSA $]_{i n i}^{\text {sol }}$, of 1 $\mathrm{mg} / \mathrm{ml}$ was prepared by dilution in PBS. The scaffold-cum-gel constructs were then submerged in the BSA solution $\left(1.6 \mathrm{ml}\right.$ per piece, $\left.V^{\text {sol }}\right)$ and left overnight at $37^{\circ} \mathrm{C}$, allowing the load of BSA into the gel. During this time, the scaffolds were held upright in the vials with the help of a metal needle. Immediately after absorption (to avoid gel drying), each BSA-filled scaffold-cum-gel piece was placed upright in a vial with $1.2 \mathrm{ml}$ of PBS at $37^{\circ} \mathrm{C}$ to follow the BSA release from the gel.

The supernatant was collected at pre-selected time intervals (every hour during the first 8 $\mathrm{h}$, and every $24 \mathrm{~h}$ from this moment on) up to 10 days and replaced with fresh PBS tempered at $37^{\circ} \mathrm{C} .1 \mathrm{ml}$ of each supernatant, $V^{\text {s.natant }}$, was allowed to react with $\mathrm{BCA}$ 
reactant (Thermo Scientific) in a 1:1 volume ratio for $1 \mathrm{~h}$ at $60^{\circ} \mathrm{C}$. The mixtures, giving a purple colour with absorbance at $562 \mathrm{~nm}$ proportional to the BSA concentration, were scanned in an ultraviolet spectroscope (Cecil CE9200, Aquarius). A standard calibration curve was obtained with solutions of known concentrations of BSA, [BSA], up to 50 $\mu \mathrm{g} / \mathrm{ml}$. This standard curve allowed to correlate the absorbance at each time with the mass of BSA released in each period, making use of the supernatant volume: $[\mathrm{BSA}] \cdot V^{\text {s.natant }}$.

In parallel, the BSA solution exhausted after the overnight load was diluted as needed and analysed as described above by UV spectrophotometry and with the help of the calibration curve to determine the residual concentration, $[\mathrm{BSA}]_{\text {res }}^{\text {sol }}$. The amount of BSA initially loaded in the gel within the pores of the scaffolds, $M_{0}$, was calculated as the difference between the initial BSA mass in the loading solution and the mass remaining in the solution after sorption overnight, $M_{0}=\left([\mathrm{BSA}]_{i n i}^{\text {sol }}-[\mathrm{BSA}]_{r e s}^{\text {sol }}\right) \cdot V^{\text {sol }}$. The cumulative mass released up to time $t, M_{t}$, was divided by $M_{0}$ to obtain the percentage of BSA released at each time.

\subsection{Cell-seeding issues and cell cultures in the scaffold-cum-gel constructs}

Commercial L929 mouse fibroblasts from subcutaneous connective tissue, areolar and adipose (Sigma Aldrich) in their $10^{\text {th }}$ passage were employed for preliminary in vitro tests. The bare scaffolds were sterilized previously with a $25 \mathrm{kGy}$ dose of gamma radiation from a ${ }^{60}$ Co source (Aragogamma, Barcelona, Spain). L929 cells were seeded in two series of materials: scaffolds whose pores had been filled with a non-gelled 0.15 $\%(w / v)$ SAP solution with the help of some vacuum were compared with scaffolds whose pores had been previously filled with PBS. Two seeding methodologies were 
compared. (a) In the one hereafter called "static seeding", $10^{5}$ cells were seeded on the upper-surface of each piece of scaffold having a diameter of $8 \mathrm{~mm}$ in a 48 -well tissue plate, suspended in $20 \mu \mathrm{l}$ of a $10 \%$ sucrose (Sigma-Aldrich) acqueous solution. The samples were kept for $30 \mathrm{~min}$ in the incubator at $37^{\circ} \mathrm{C}$, and then $380 \mu \mathrm{l}$ of culture medium consisting in DMEM high glucose supplemented with 10\% FBS, 1\% penicillin-streptomycin and $1 \%$ L-glutamine (Sigma) were added to each well. $(b)$ In the "dynamic seeding" methodology, the cells were seeded on the scaffolds in the same number and way as above, but then the culture plate was smoothly shaken in a Titramax 101 shaker (Heidolph instruments, Germany) for $30 \mathrm{~min}$; then, $380 \mu \mathrm{l}$ of culture medium were added to each well. The scaffolds seeded in both ways were cultured at $37^{\circ} \mathrm{C}$ in a humidified atmosphere under $5 \% \mathrm{CO}_{2}$ for 1,3 and 7 days. The culture medium was renewed every 2-3 days.

In order to confirm that the assembly conditions established with the L929 cell line were effective also with the cells employed in a big animal model of myocardial infarction the procedures were repeated with adipose-tissue derived stem cells (ASCs). ASCs were provided by the Hôpital Georges Pompidou (Paris); they were isolated from fat biopsies of the right thoracic wall of female Rambouillet sheeps as described in [32]. ASCs were seeded in a $20 \mu \mathrm{l}$ sucrose-enriched aqueous droplet after the loading of the peptide. After a smooth shaking, $380 \mu \mathrm{l}$ of culture medium was added and the culture was prolonged for 7 days.

\subsection{Analysis of the cell distribution in the scaffold-cum-gel constructs}

After culture, cell proliferation and distribution were observed by fluorescence (Leica DM6000) or confocal laser scanning microscopy (Olympus, FV1000). Previously, the samples were rinsed with PBS, fixed with $4 \%$ paraformaldehyde (PFA; Panreac) for 20 
min at room temperature, and washed twice with PBS for 5 min. Cells were permeabilized with 0.1 vol\% Triton $\mathrm{X}-100$ for $30 \mathrm{~min}$ at room temperature. After two rinses with DPBS, the samples were incubated with BIODIPY-FL phallacidin (Invitrogen, 1:200) and vimentin (Sigma, 1:100) for $1 \mathrm{~h}$ at room temperature in the dark, next washed twice with DPBS and counterstained for 5 min with 4',6-diamidino-2phenylindole dihydrochloride (DAPI; Sigma, 1/5000). The pieces were rinsed twice with PBS, cryopreserved in $30 \%$ sacarose and finally cut in $100 \mu \mathrm{m}$ slices. For microscopy observation, the slices were mounted with Fluorsave reagent (Calbiochem) coverslipped, and stored in the dark at $4^{\circ} \mathrm{C}$ until use.

The morphology of the cells was observed by scanning electron microscopy (SEM) in a JSM-5410 microscope. For this, samples were fixed with $3.5 \%$ glutaraldehyde (GTA; Scharlab) for $60 \mathrm{~min}$ at $37^{\circ} \mathrm{C}$, followed by two rinsings with PBS. Next, samples were incubated with $2 \%$ osmium tetraoxide for $2 \mathrm{~h}$ at room temperature followed by four rinses with distilled water. Afterwards, samples were dehydrated through a series of graded ethanol $(30,50,70,96$, and 100$)$ at $4^{\circ} \mathrm{C}$. Samples were finally dried by criticalpoint drying and sputter-coated with gold to be observed by SEM at $15 \mathrm{kV}$ and $15 \mathrm{~mm}$ of working distance.

\section{Results}

\subsection{Morphology and physical properties of the scaffold-cum-gel constructs}

PEA scaffolds obtained by the inverse template technique have interconnected spherical pores, which leave trabeculae as they intersect (Figure 1). The measured pore volume fraction of the structure is $80.8 \pm 3.5 \%$, and the average pore diameter of $90.96 \pm 6.91$ $\mu \mathrm{m}$. The equilibrium water content of 2DPEA, attained after 3 days of immersion in 
PBS, resulted in $1.14 \pm 0.16 \%$. The water contact angle on 2DPEA is characteristic of a hydrophobic difficult to wet material, $72.9 \pm 4.1^{\circ}$.

Natural diffusion was not enough to fill the scaffolds with the peptide solution due to their hydrophobicity, and alternative loading procedures were proposed. The application of pressure to force the solution to penetrate into the pores yielded heterogeneously filled scaffolds, even after a subsequent centrifugation. The plasma-assisted procedure, though effective to hydrophilize the surface of the scaffolds, does not seem to be a viable strategy in the clinical practice. For these reasons, these methods were not further considered. The third procedure described above to incorporate the SAP consisted in the introduction of the scaffold in a syringe with the peptide solution and helping the intrusion of the solution by evacuation. This method allowed to completely fill the scaffold pores with the SAP solution. The solution could be brought to gelation in situ within the pores in 30 minutes. No differences were observed with those samples gelled for longer times; thus, 30 min was hereafter the gelation time employed. When water sublimates for cryoSEM observation, the trace of the non-gelled SAP solution appears as parallel walls (Figure $2 \mathrm{~b}$ ); once gelled, the SAP nanofibrilar network leaves a honeycomb-like structure in the pores of the scaffolds (Figure $2 \mathrm{c}$ and $\mathrm{d}$ ). These structures cannot be observed after water sublimation in the scaffold's pores containing PBS (Figure 2 a). Macroscopically, Congo red stains the gel within the pores in red, demonstrating the formation of a $\beta$-sheet structure, in contrast with the scaffolds containing only PBS, which remain white (insets of Figure 2 a and c).

The compression curves of the scaffolds, either bare, filled with water or filled with the RAD16-I solution and gelled with PBS, show an overall non-linear dependence of stress upon strain with increasing modulus, Figure 3. A first linear deformation region ranges up to $5 \%$ strain and $10 \mathrm{kPa}$ stress, followed by a region of increasing slope, which 
stabilizes in a second linear deformation region for strains greater than $25 \%$ at stresses above $100 \mathrm{kPa}$. The Young moduli in both linear deformation regimes are included as insets in Figure 3. Those of the scaffolds filled with water were found to be $0.053 \pm 0.01$ MPa and $0.63 \pm 0.15 \mathrm{MPa}$, respectively. The moduli of the scaffolds filled with the gelled peptide are slightly greater than those of bare or filled with water ones.

\subsection{BSA uptake and release from the scaffold-cum-gel constructs}

The concentration of BSA incorporated to the scaffold's pores, obtained from the mass uptake $M_{0}$ and the volume of SAP solution in the pores, resulted in $12.7 \mathrm{mg} / \mathrm{ml}$. Unexpectedly, this value is much higher than that of the starting BSA solution, $1 \mathrm{mg} / \mathrm{ml}$. Figure 4 shows the fractional BSA, $M_{t} / M_{0}$, release curve of the loaded construct, where $M_{0}$ is the initial mass of BSA in the scaffold-cum-gel construct, and $M_{t}$ is the mass released from it at time $t$. Two different release regimes can be identified: first a fast protein release up to $14.9 \%$ of the initial amount of BSA within the first eight hours, and then a slower one from this moment on up to $25 \%$ in 10 days. The initial release regime can be successfully fitted to the power law $M_{t} / M_{0}=0.0785 * t^{0.33}$, with time $t$ in hours; the second release one is almost linear in time and follows $M_{t} / M_{0}=0.0004 * t+0.1493$, for $t$ greater than $8 \mathrm{~h}$.

\subsection{Cell-seeding and cell cultures in the scaffolds and scaffold-cum-gel constructs}

Bare scaffolds filled with PBS and scaffolds filled with the SAP solution were seeded on their upper surface with fibroblasts in an aqueous droplet with sucrose. In previous tests cells were seeded with culture medium, but this provoked the gelation of the peptide as cells started to diffuse through it, which impeded a homogeneous colonization of the scaffold. 
After seeding, cells were allowed to diffuse within the scaffold with or without mechanical assistance, and after 30 min culture medium was added to induce gelation. Figures 5 to 7 show that more cells colonize the scaffolds when the scaffold's pores are filled with the SAP gel, and consequently after 7 days they have proliferated and occupy all the pores. Comparison of the images obtained from scaffolds seeded statically and dynamically clearly indicates that the dynamic seeding favors the invasibility of the pores by the cells, which remain encapsulated when the peptide fills the pores, proliferate and are much more numerous after 7 days. Dynamic cell seeding for scaffolds containing the SAP gel leads after 1 day to a uniform distribution of the cells throughout the scaffold, Figure 7. The cells seem to be leaning on the polymeric trabeculae at this culture time (see the arrowheads pointing at cells around a spherical pore in Fig. 7), and at 7 days completely invade the lumen of the pores (the area occupied by the scaffold is clearly seen in dark -see the asterisks-, delimiting the stained cells in the pores). At this culture time the cells display under SEM either an elongated or a more rounded morphology (Figure 8 a, see the broken line outlining a pore, and the asterisk, respectively), depending on whether they adhere to the PEA trabeculae or swim within the pores, and they have synthesized a large amount of extracellular matrix. More closely (Figure $8 \mathrm{~b}$ ), such rounded cells seem to be embedded in what is probably ECM and SAP gel completely filling the pores of the scaffold.

Sheep ASCs intended for preclinical studies were also able to invade uniformly the whole scaffold when they were seeded after the SAP pre-load, despite their larger dimensions (Figure 9). After 7 days, the scaffolds showed a large and homogeneously distributed population of cells occupying completely the free spaces and even covering both faces of the scaffold. 


\section{Discussion}

The results of our study show that it is feasible to combine SAP hydrogels and elastomeric hydrophobic scaffolds into constructs having some of the distinctive advantages of both kinds of materials, thus producing vehicles for cell seeding and cell supply with unique properties: a cell-friendly, ECM-like immediate microenvironment for the cells that facilitates an efficient and uniform cell colonization of the scaffolds, plus shape stability, mechanical consistency and strength. Furthermore, these constructs do also possess interesting features as active molecules delivery platforms. In the following we discuss briefly these aspects.

The concentration of SAP in the prepared solutions $(0.15 \% \mathrm{w} / \mathrm{v})$ for injection in the scaffolds' pores is so low that it essentially has the density and viscosity of liquid water; after gelling, the viscosity is somewhat greater, but still the SAP hydrogel has the rheological properties of a mucus, and thus negligible resistance to shearing and tensile stresses, and to manipulation in general. The scaffold-cum-gel construct represents, in this mechanical respect, an improvement of several orders of magnitude: from moduli values typical of a mucus (10 to $80 \mathrm{~Pa}$ ) we pass to values typical of an elastomer (of the order of $1 \mathrm{MPa}$ ) (Figure 3), and obtain a manipulable construct, able to withstand tractions, compressions and shears to the extent that a typical elastomer scaffold does. The presence in the scaffold's pores of the filler gel yields a somewhat higher modulus in compression. This effect can be attributed mainly to the presence of water in the pores, which is very incompressible, and to its relative difficulty to flow out of the pores upon compression; the gelled state of the SAP results in a somewhat more hindered flow, which translates into somewhat higher linear moduli. This phenomenon is known as poroelasticity, and it is typical of fluid-filled porous media under compression [33,34]. In 
our experiments the mechanical effect of the filling gel is manifest already at low strains, and persists in the linear deformation region.

The scaffold-cum-gel construct is useful also as a platform for drug and molecule delivery, independently of the presence of cells. BSA was employed in this study as a model protein for uptake and release. The SAP hydrogel can be considered as a twophase system, one phase being a water solution of non-assembled SAP molecules, the other phase constituted by the assembled SAP molecules into a nanofibrilar network. The BSA molecules sorbed in the scaffold-cum-gel construct may be thought to reside in three different placements: either solved in the bulk of the watery phase inside the pores, or located in the assembled phase, or, finally, adsorbed onto the surface of the scaffold's pores. The initial concentration of BSA in the construct was estimated by means of $M_{0}$, the mass of gel entrapped in the scaffold, $m^{g e l}$, and assuming that the density of the gel is close to that of water: $[\mathrm{BSA}]_{i n i}^{\text {construct }}=M_{0} / V^{\text {gel }}=M_{0} \cdot \rho^{\text {gel }} / \mathrm{m}^{\text {gel }}$. This calculus resulted in a value of $12.7 \mathrm{mg} / \mathrm{ml}$, which is much higher than that of the starting solution from which the uptake took place, $1 \mathrm{mg} / \mathrm{ml}$. Firstly, this finding confirms that the protein can be easily and efficiently entrapped after the formation of the gel. Secondly, it indicates that the construct is able to concentrate the BSA solution (which might be another useful property for some applications). Since, by thermodynamic equilibrium, the concentration of BSA molecules able to diffuse freely must be similar in the gel phase inside the pores and in the outside watery phase, this difference is indicative of BSA molecules in the construct residing preferentially either adsorbed on the PEA surfaces or trapped within the microphase constituted by the assembled microfibrils. Our experiments are insufficient to establish the relative importance of both entrapment modes, and further characterization would be in need on this point. The BSA molecule may indeed interact electrostatically with the peptide 
chains; the amide and acid groups of its molecular structure yield a different net charge of the BSA molecule at different $\mathrm{pH}$ values, its isoelectric point being 4.2 [35]. During the BSA uptake process, which takes place above this $\mathrm{pH}$, the molecule is negatively charged and thus may interact with residual positively charged groups of the SAP macromolecules. A supporting result is found in [36]: with increasing $\mathrm{pH}$, the ionization of the acid groups of the protein and the poly(acrylic acid) in which it was entrapped increased the repulsion forces between them, and consequently reduced the free space available for the protein molecules in the gel network.

The BSA loaded constructs are able to release the protein when immersed in PBS. The kinetics of this release has two clearly differentiated time regimes, Figure 4. A faster release kinetics occurs within the first eight hours, time at which about a $15 \%$ of the total BSA amount is released; from that time on a much slower kinetics is in act. The residual BSA remaining after 10 days was still $75 \%$ of the initial amount, and the plot didn't show yet any decrease of the time rate of release. A good fit of the first stage of the time-release curve to a power law was obtained, $M_{t} / M_{\infty}=k \cdot t^{n}$ (inset in Figure 4); least-squares fitted values of the $k$ and $n$ parameters turned out to be 0.078 and 0.33 , respectively. A value of $n=0.5$ corresponds to Fickian diffusion from a slab; that is, the case in which the release is controlled by a pure diffusion process, a concentration gradient equalization due to random brownian motion of the molecules, with no bias in their displacements (Fickian diffusion from a cylinder has $n=0.45$, and from a sphere $n$ $=0.43)$ [37]. This is here not the case. The fitting of the power law to the second release regime gives $n=1$ (linear growth with time of the amount released) and $k=0.0004$ (plus the new parameter $\alpha=0.1493$ needed to account for the initial release). Power laws such as the stated one are typically used to describe solvent release from hydrogels [38-40]; the parameter $k$ is then interpreted as a structural/geometric factor to account 
for the different tortuosities of the transport path. In [38], the authors followed the release of BSA from previously dried poly(N-isopropylacrylamide) hydrogels, which lasted barely $2 \mathrm{~h}$ at $40^{\circ} \mathrm{C}$, and obtained higher values for the $k$ and $n$ parameters of 0.112 and 0.462 , respectively. Other BSA-gel systems have also been found to exhibit double kinetics of BSA release, which have been interpreted as an indication of the interference with diffusion-controlled transport of further mechanisms: swelling or shrinking of the gel matrix (sometimes triggered by $\mathrm{pH}$ or temperature changes in the environment) $[38,39,41]$, chemical reactions (polymer degradation, drug-polymer interaction, etc.) $[36,39,42]$, and processing (heterogeneous cross-linking of the gel, entrapment of the drug on the surface, use of solvents afterwards dried, etc.) or storage conditions (drug saturation at the surface on gel drying, drug migration, etc.) leading to an uneven drug distribution [43]. When hydrogel samples are dried after the protein loading, their swelling usually provokes a burst release [36,38], due to those molecules near the polymer surface and rapidly transferred to the medium. This is obviously not the case here, as the constructs were not dried after the protein loading. The rapid initial kinetics observed in our system could be related to the electrostatic interactions between the BSA molecules and the oligopeptides forming the gel fibrils. As previously discussed, the excess of BSA within the scaffold-cum-gel construct over the initial concentration of the uptake solution must be attributed to specific interactions of BSA molecules with the PEA polymer chains, or with the assembled SAP molecules, or with both. Thus, release of BSA solved in the watery phase of the hydrogel may be expected to be faster than the release of BSA molecules which are either linked to the peptide nanofibrillar assemblies or adsorbed to the PEA surfaces. A slower release of these BSA molecules must follow, since those specific bonds must be eased. 
A further effect of pore filling with the SAP gel is to improve cell distribution after seeding within the scaffolds. The presence of the (non-gelled) SAP solution within the scaffolds' pores improved fibroblasts colonization in terms of number of cells and uniformity of their distribution. The SAP solution acted as a faster medium for cell invasion of the pores of the scaffolds than mere culture medium (Figure 7, 1 day). At 7 days the cells had proliferated much more when the pores were filled with the SAP gel (Figure 7, 7 days, and Figure 8). The dynamic seeding achieved better results than the conventional one; 30 min of smooth shaking were enough to facilitate cell diffusion throughout the scaffolds and a uniform distribution. The advantage of the SAP filling for cell colonization may be due to the higher diffusion speed of the cells in this medium than on the scaffolds surfaces: PEA is a hydrophobic polymer onto which most cells are willing to adhere and spread, thus delaying their progress through the structure. Swimming through the peptide solution seems a faster way of colonization than creeping on the scaffold's pores surfaces. In our experiments, the cells were seeded with the minimum amount of medium, and planted as a droplet onto the SAP-filled scaffold; this procedure avoids their spilling out of the scaffold and optimizes cell seeding. The SAP was gelled later, consequently entrapping the cells inside the pores. This seeding procedure was also successful with ASCs, a larger kind of cell that is currently being employed in a preclinical study in a sheep animal model of chronic infarction; sheep ASCs were incorporated at a high density to the SAP pre-loaded scaffolds, and allowed to invade completely the volume occupied by the peptide solution with the help of a smooth shaking before gelation.

The scaffold-cum-gel constructs here developed provide to the cells seeded in them a friendly immediate ECM-like environment through the SAP gel component, while at the same time possess enough mechanical integrity and shape stability thanks to the 
embracing elastomeric scaffold. The ECM-like SAP gel can surround the cells, improving the survival and migration conditions, and can, at the same time, incorporate and deliver active molecules such as drugs or growth factors in a controlled manner to regulate cell fate or stimulate an angiogenic response. 


\section{Conclusions}

SAP solutions can be effectively incorporated and gelled within the pores of elastomeric scaffolds. These constructs can then be seeded in a more efficient manner than bare scaffolds, probably because the hydrogel represents a better migration medium for cells. The scaffold-cum-gel platform can also be employed as a protein delivery vehicle with unique features. In summary, these constructs combine several advantages of their separate components yielding easy-to-produce and to manipulate systems for cell and factor delivery. 


\section{Acknowledgements}

The authors acknowledge funding through the European Commission FP7 project RECATABI (NMP3-SL-2009-229239), and from the Spanish Ministerio de Ciencia e Innovación through projects MAT2011-28791-C03-02 and -03. Dr. J C Chachques (Hôpital Européen Georges Pompidou, Paris) is thanked for providing the ASCs employed in this study.

\section{References}

1. Arnal Pastor M, Vallés Lluch A, Keicher M, Monleón Pradas M. Coating typologies and constrained swelling of hyaluronic acid gels within scaffold pores. J Colloid Interf Sci 2011;361:361-369.

2. Blan NR, Birla RK. Design and fabrication of heart muscle using scaffold based tissue engineering. J Biomed Mater Res 2008;86A:195-208.

3. Antunes JC, Oliveira JM, Reis RL, Soria JM, Gómez-Ribelles JL, Mano JF. Novel poly(L-lactic acid)/hyaluronic acid macroporous hybrid scaffolds: characterization and assessment of cytotoxicity. J Biomed Mater Res 2010;94A:856-869.

4. Zhao X, Zhang S. Self-assembling nanopeptides become a new type of biomaterial. Adv Polym Sci 2006;203:145-170.

5. Jung JP, Gasiorowski JZ, Collier JH. Fibrillar peptide gels in biotechnology and biomedicine. Pept Sci 2010;94:49-59.

6. Zhang S, Gelain F, Zhao X. Designer self-assembling peptide nanofiber scaffolds for 3D tissue cell cultures. Semin Cancer Biol 2005;15:413-420. 
7. Takei J. 3-Dimensional culture scaffold for everyone: drug screening, tissue engineering and cancer biology. AATEX 2006;11:170-176.

8. Quintana L, Fernández Muiños T, Genové E, Olmos MM, Borrós S, Semino CE. Early tissue patterning recreated by mouse embryonic fibroblasts in a threedimensional environment. Tissue Eng Part A 2008;14:1-10.

9. Ortinau S, Schmich J, Block S, Liedmann A, Jonas L, Weiss DG, et al. Effect of 3Dscaffold formation on differentiation and survival in human neural progenitor cells. Biomed Eng Online 2010;9:70.

10. Sieminski AL, Semino CE, Gong H, Kamm RD. Primary sequence of ionic selfassembling peptide gels affects endothelial cell adhesion and capillary morphogenesis. J Biomed Mater Res Part A 2008;87:494-504.

11. Genové E, Shen C, Zhang S, Semino CE. The effect of functionalized selfassembling peptide scaffolds on human aortic endothelial cell function. Biomaterials 2005;26:3341-3351.

12. Narmoneva DA, Vukmirovic R, Davis ME, Kamm RD, Lee RT. Endothelial cells promote cardiac myocyte survival and spatial reorganization. Circulation 2004;110:962-968.

13. Thonhoff JR, Lou DI, Jordan PM, Zhao X, Wu P. Compatibility of human fetal neural stem cells with hydrogel biomaterials in vitro. Brain Res 2008;1187:42-51.

14. Holmes TD, Lacalle S, Su X, Liu G, Rich A, Zhang S. Extensive neurite outgrowth and active synapse formation on self-assembling peptide scaffolds. PNAS 2000;97:6728-6733.

15. Tokunaga M, Liu ML, Nagai T, Iwanaga K, Matsuura K, Takahashi $\mathrm{T}$, et al. Implantation of cardiac progenitor cells using self-assembling peptide improves cardiac function after myocardial infarction. J Mol Cell Card 2010;49:972-983. 
16. Yamaoka H, Asato H, Ogasawara T, Nishizawa S, Takahashi T. Cartilage tissue engineering using human auricular chondrocytes embedded in different hydrogel materials. J Biomed Mater Res Part A 2006;78:1-11.

17. McGrath AM, Novikova LN, Novikov LN, Wiberg M. BD PuraMatrix ${ }^{\mathrm{TM}}$ peptide hydrogel seeded with Schwann cells for peripheral nerve regeneration. Brain Res Bull 2010;83;207-213.

18. Pérez Olmedilla M, García-Giralt N, Monleón Pradas M, Benito Ruiz P, Gómez Ribelles JL, Cáceres Palou E, et al. Response of human chondrocytes to a nonuniform distribution of hydrophilic domains on poly(ethyl acrylate-co-hydroxyethyl methacrylate) copolymers. Biomaterials 2006;27:1003-1012.

19. Campillo-Fernández AJ, Pastor S, Abad-Collado M, Bataille L, Gómez Ribelles JL, Meseguer Dueñas JM, et al. Future design of a new keratoprosthesis. Physical and biological analysis of polymeric substrates for epithelial cell growth. Biomacromolecules 2007;8:2429-2436.

20. Campillo-Fernández AJ, Unger RE, Peters K, Halstenberg S, Santos M, Salmerón Sánchez M, et al. Analysis of the biological response of endothelial and fibroblast cells cultured on synthetic scaffolds with various hydrophilic/hydrophobic ratios. Influence of fibronectin adsorption and conformation. Tissue Eng 2009;15:13311341.

21. Soria JM, Martínez-Ramos C, Benavent V, Campillo-Fernández A, Gómez-Ribelles JL, Salmerón-Sánchez M, et al. Survival and differentiation of embryonic neural explants onto different biomaterials. J Biomed Mater Res Part A 2006;79:495-502.

22. Soria JM, Martínez Ramos C, Bahamonde O, García Cruz DM, Salmerón Sánchez M, Casas C, et al. Influence of the substrate's hydrophilicity on the in vitro Schwann cells viability. J Biomed Mater Res Part A 2007;83:463-470. 
23. Martínez-Ramos C, Lainez S, Sancho-Bielsa F, García Esparza A, Planells-Cases R, García Verdugo JM, et al. Differentiation of postnatal neural stem cells into glia and functional neurons on polymeric substrates. Tissue Eng 2008;14:1365-1375.

24. Martínez-Ramos C, Vallés-Lluch A, García Verdugo JM, Gómez Ribelles JL, Barcia Albacar JA, Baiget Orts A, et al. Channeled scaffolds implanted in adult rat brain. J Biomed Mater Res A 2012;100:3276-3286.

25. Rico P, Rodríguez Hernández JC, Moratal D, Monleón Pradas M, Salmerón Sánchez M. Substrate-induced assembly of fibronectin into networks. Influence of surface chemistry and effect on osteoblast adhesion. Tissue Eng 2009;15:3271-3281.

26. Soria JM, Sancho-Tello M, García Esparza MA, Mirabet V, Bagan JV, Monleón M, et al. Biomaterials coated by dental pulp cells as substrate for neural stem cell differentiation. J Biomed Mater Res Part A 2011;97:85-92.

27. Ying M, Saha K, Bogatyrev SR, Yang J, Hook AL, Kalcioglu ZI, et al. Combinatorial development of biomaterials for clonal growth of human pluripotent stem cells. Nature Materials 2010;9:768-778.

28. Campillo Fernández AJ, Arredondo Zamudio AA, Gallego Ferrer G, Monleón Pradas M, Carda Batalla MC. Polymeric scaffolds for guided dentine regeneration. Int J Artif Organs 2005;28:362.

29. Brígido Diego R, Pérez Olmedilla M, Serrano Aroca A, Gómez Ribelles JL, Monleón Pradas M, Gallego Ferrer G, et al. Acrylic scaffolds with interconnected spherical pores and controlled hydrophilicity for tissue engineering. J Mater Sci: Mater Med 2005;16:693-698.

30. Más Estellés J, Krakovsky I, Rodríguez Hernández JC, Piotrowska AM, Monleón Pradas M. Mechanical properties of porous crosslinked poly(ethyl-acrylate) for tissue engineering. J Mater Sci 2007;42:8629-8635. 
31. Rodríguez Hernández JC, Serrano Aroca A, Gómez Ribelles JL, Monleón Pradas M. Three-dimensional nanocomposite scaffolds with ordered cylindrical orthogonal pores. J Biomed Mater Res B Appl Biomater 2008;84:541-549.

32. Shafy A, Fink T, Zachar V, Lila N, Carpentier A, Chachques JC. Development of cardiac support bioprostheses for ventricular restoration and myocardial regeneration. Eur J Cardiothorac Surg 2013;43:1211-1219.

33. Detournay E, Cheng AH-D. Fundamentals of poroelasticity. In: Fairhurst C, editor. Comprehensive rock engineering: principles, practice and projects, vol. II, Analysis and design method. New York: Pergamon Press, 1993. pp. 113-171.

34. Fornells P, García-Aznar JM, Doblaré M. A finite element dual porosity approach to model deformation-induced fluid flow in cortical bone. Ann Biomed Eng 2007;35:1687-1698.

35. Jiang W, Schwendeman S. Stabilization and controlled release of bovine serum albumin encapsulated in poly(D, L-lactide) and poly(ethylene glycol) microsphere blends. Pharmaceut Res 2001;18:878-885.

36. Khoury C, Adalsteinsson T, Johnson B, Crone WC, Beebe DJ. Tunable microfabricated hydrogels - A study in protein interaction and diffusion. Biomed Microdev 2003;5:35-45.

37. Ritger PL, Peppas NA. A simple equation for description of solute release. I. Fickian and non-Fickian release from non-swellable devices in the form of slabs, spheres, cylinders or discs. J Controlled Release 1987;5:23-36.

38. Naddaf AA, Tsibranska I, Bart HJ. Kinetics of BSA release from poly(Nisopropylacrylamide) hydrogels. Chem Eng Proc 2010;49:581-588.

39. Lin C-C, Metters AT. Hydrogels in controlled release formulations: network design and mathematical modeling. Adv Drug Deliv Rev 2006;58:1379-1408. 
40. Masaro L, Zhu XX. Physical models of diffusion for polymer solutions, gels and solids. Prog Polym Sci 1999;24:731-775.

41. He H. Multifunctional medical devices based on $\mathrm{pH}$-sensitive hydrogels for controlled drug delivery. PhD dissertation, The Ohio State University, 2006.

42. Jiang W, Schwendeman S. Stabilization and controlled release of bovine serum albumin encapsulated in poly(D, L-lactide) and poly(ethylene glycol) microsphere blends. Pharmaceut Res 2001;18:878-885.

43. Huang X, Brazel CS. On the importance and mechanisms of burst release in matrix controlled drug delivery sustems. J Controlled Release 2001;73:121-136. 


\section{Figure captions}

Figure 1. SEM images of the PEA scaffolds. (a) cross section, (b) surface.

Figure 2. CryoSEM cross section images of: (a) PEA scaffold loaded with PBS, PEA scaffolds loaded with $0.15 \%$ SAP solution (b) and after gelling with PBS (c, $d$ at different magnification). Insets in (a, c) are macroscopic images of PEA scaffolds after congo red staining: (a) bare and (c) loaded with the SAP gel

Figure 3. Stress-strain curves obtained from compressive experiments performed on PEA scaffolds: bare, and filled with the SAP gel. Insets: initial Young modulus, $E_{1}$, and linear modulus $E_{2}$ calculated at strain 0.3 .

Figure 4. BSA release curve from loaded scaffold-cum-gel constructs in PBS: fractional mass $M_{t} / M_{0}$ of BSA released at time $t$ versus time $t$. Inset: fit to a power law function of the data of the initial release regime.

Figure 5. Fluorescence microscopy images of the surfaces of PEA scaffolds (without and with SAP gel within their pores) seeded with fibroblasts (statically and dynamically) and cultured for 1 day (scale bar 200 $\mu \mathrm{m})$ and 7 days (scale bar $100 \mu \mathrm{m})$; DAPI (nuclei) staining in blue.

Figure 6. Fluorescence microscope images of fibroblasts seeded statically and dynamically in PEA scaffolds with and without SAP solution in their pores, cultured for 7 days. DAPI stain for nuclei (blue), phalloidin stain for actin (green) and vimentin stain for cell membrane (red). Images correspond to $100 \mu \mathrm{m}$ thick internal slices.

Figure 7. Confocal laser microscope images of fibroblasts seeded dynamically in PEA scaffolds with the SAP gel in their pores, cultured for 1 and 7 days. DAPI stain for nuclei (blue) and phalloidin stain for actin (green). Images correspond to $100 \mu$ m-thick internal slices.

Figure 8. SEM images at different magnifications of cross sections of PEA scaffolds with SAP gel in their pores, seeded dynamically with fibroblasts and cultured for 7 days.

Figure 9. Sheep adipose-tissue derived stem cells (ASCs) seeded dynamically in a PEA scaffold filled with the SAP and cultured for 7 days: (a) CLSM image of a $100 \mu$-thick internal slice, DAPI stains for nuclei (blue) and phalloidin stains for actin (green); (b) SEM image of the surface. 
Graphical Abstract (for review)

\section{Graphical abstract}
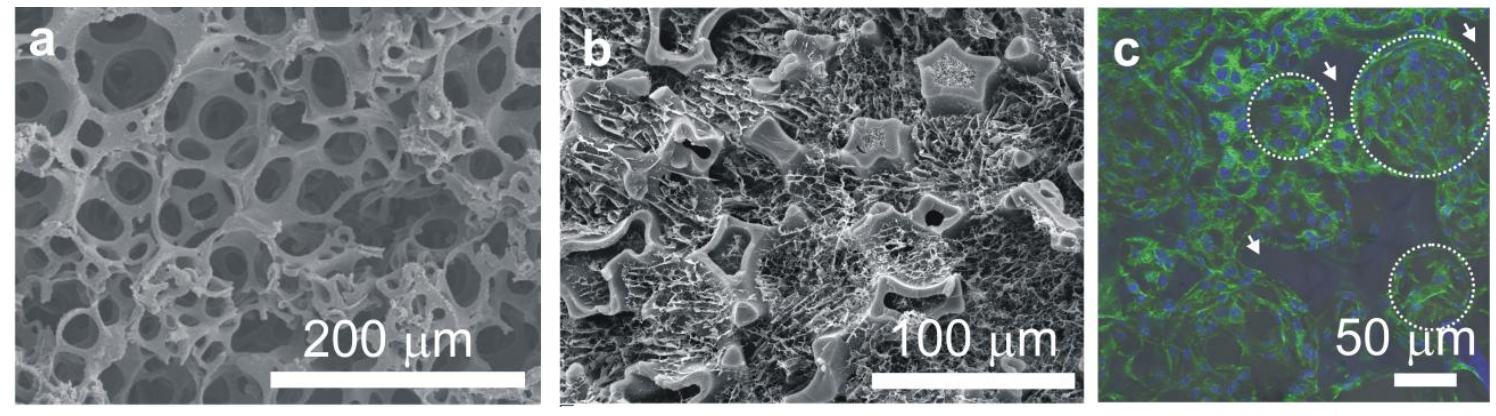

(a) SEM image of a PEA scaffold with spherical interconnected pores. (b) CryoSEM cross section image of a PEA scaffold loaded with $0.15 \%$ (w/v) SAP solution and gelled with PBS. (c) CLSM image of fibroblasts seeded dynamically in PEA scaffolds with the SAP gel in their pores, cultured for 7 days. DAPI stain for nuclei (blue) and phalloidin stain for actin (green). Image corresponds to a $100 \mu \mathrm{m}$ thick internal slice. 
Click here to download high resolution image
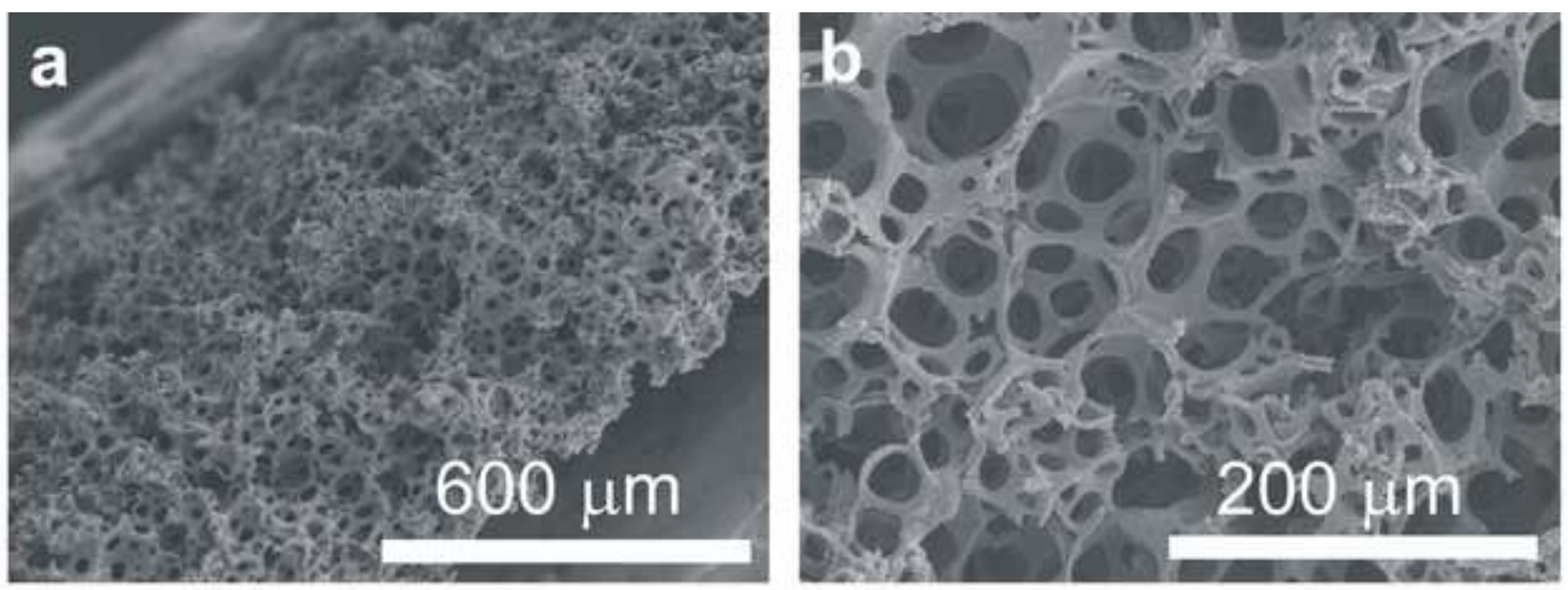

\section{.}

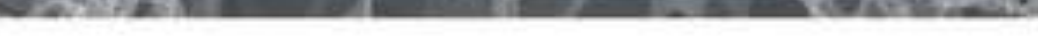


Click here to download high resolution image
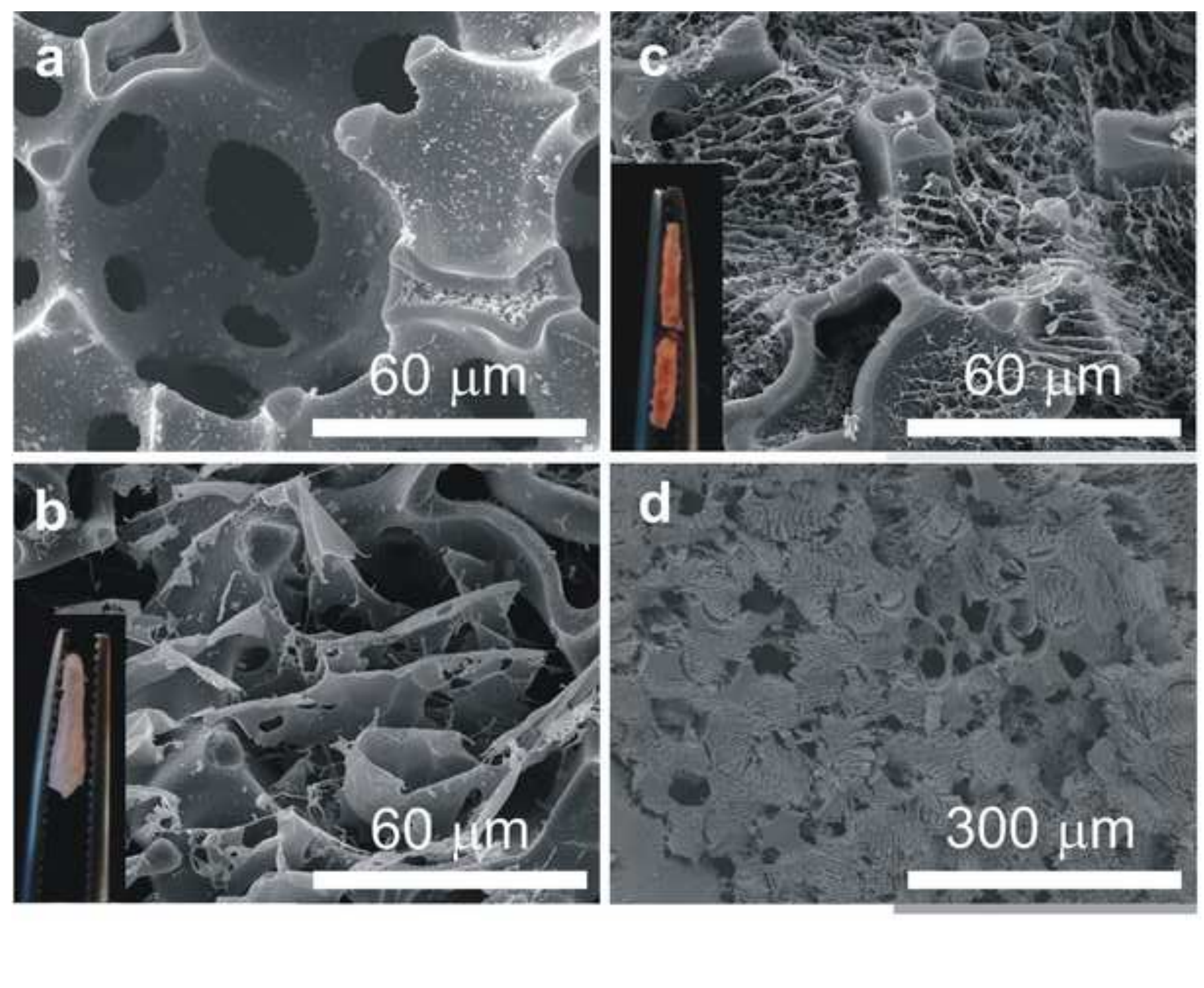


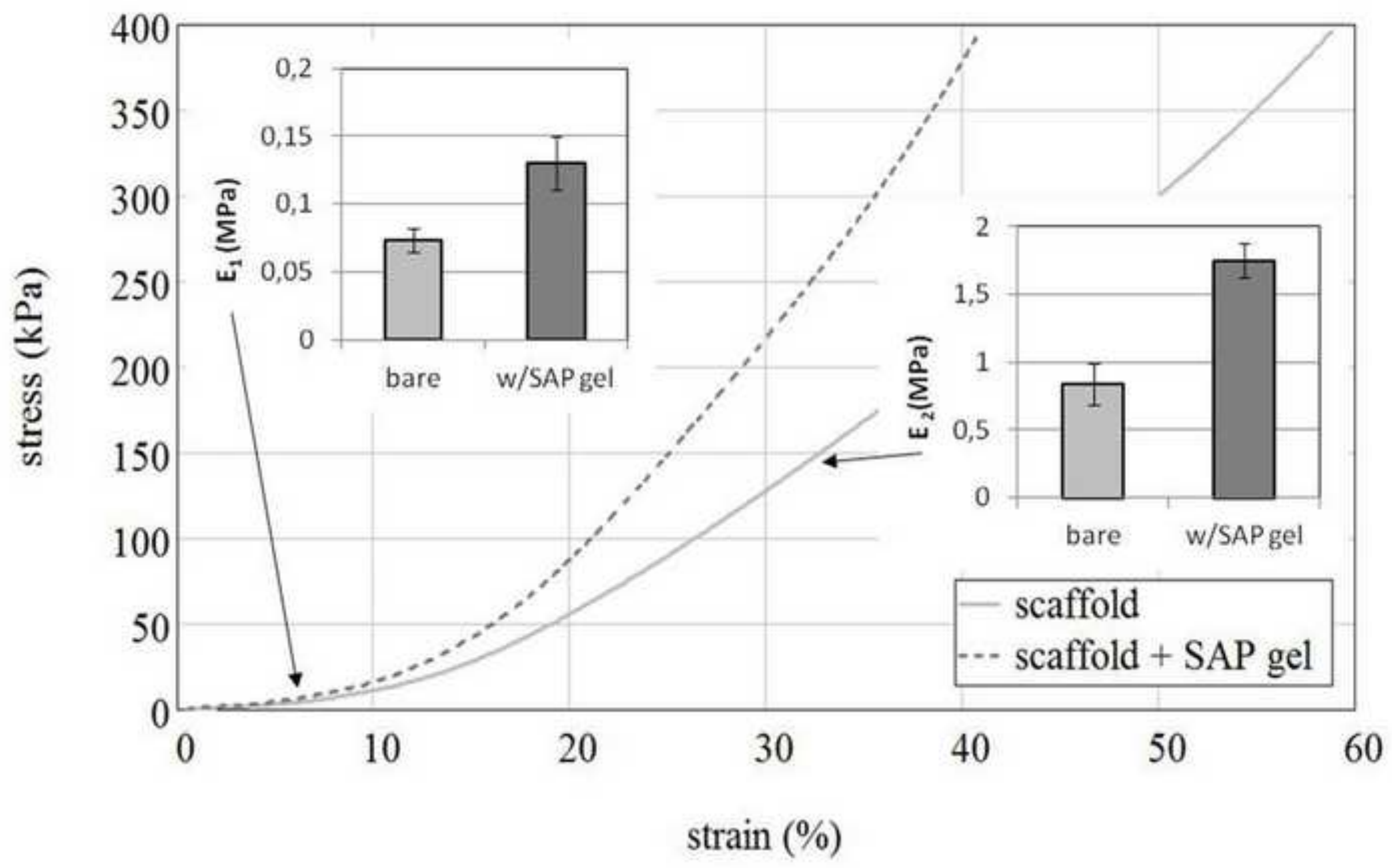


Click here to download high resolution image

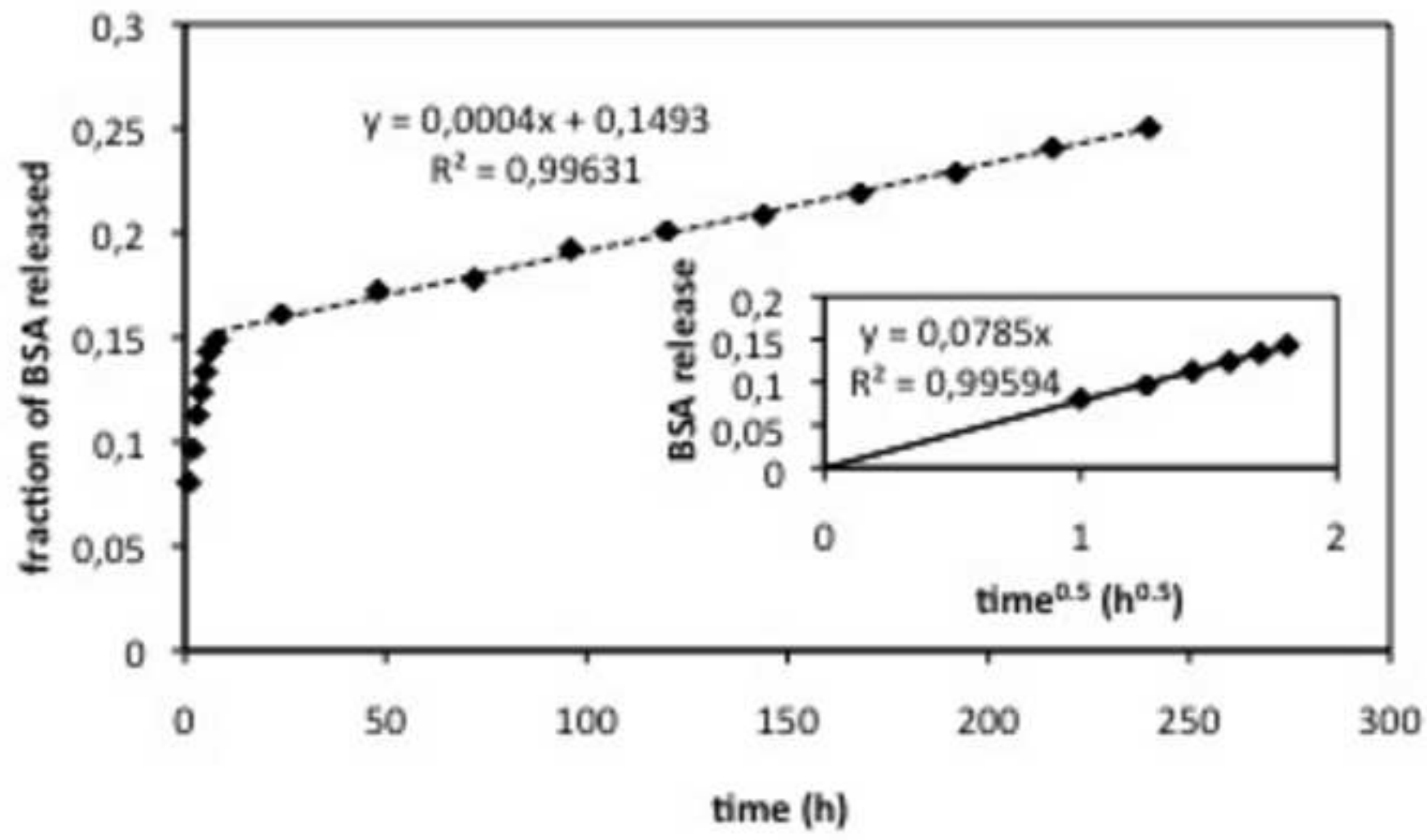

time (h) 
1 day

w/o SAPs
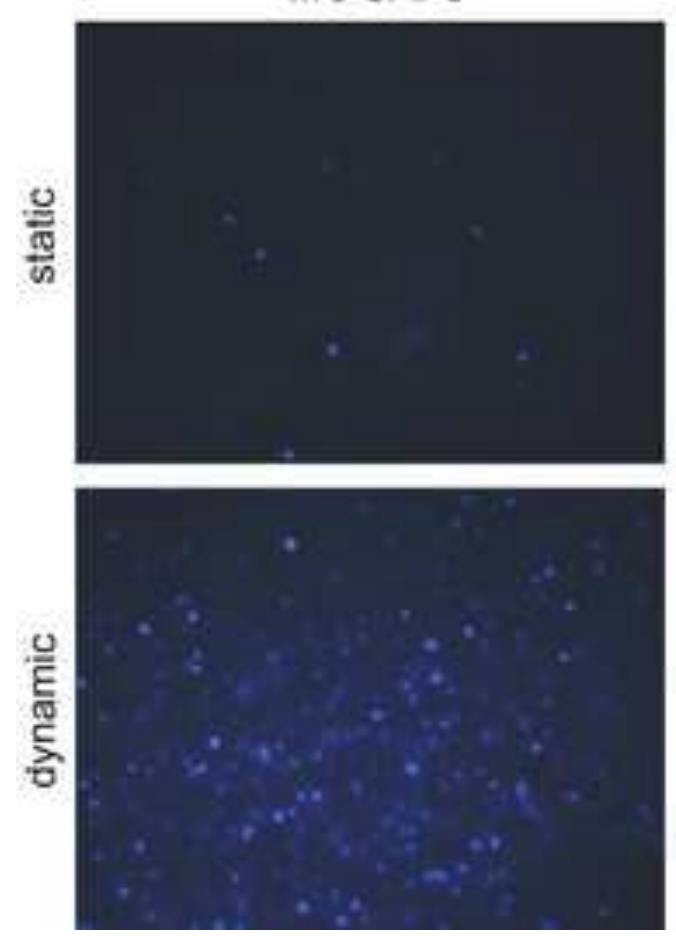

7 days

w/o SAPs
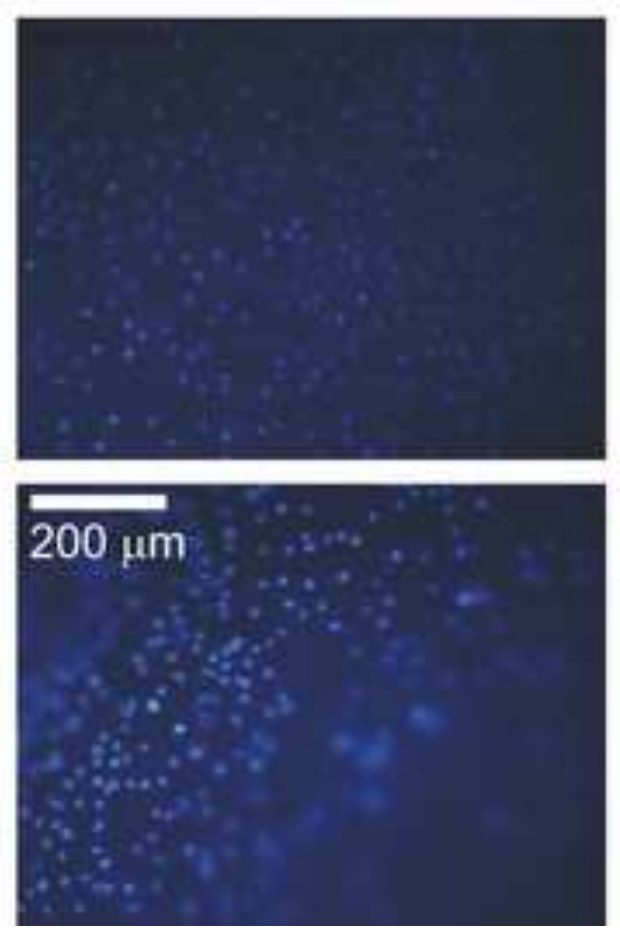

\section{wh SAPs}
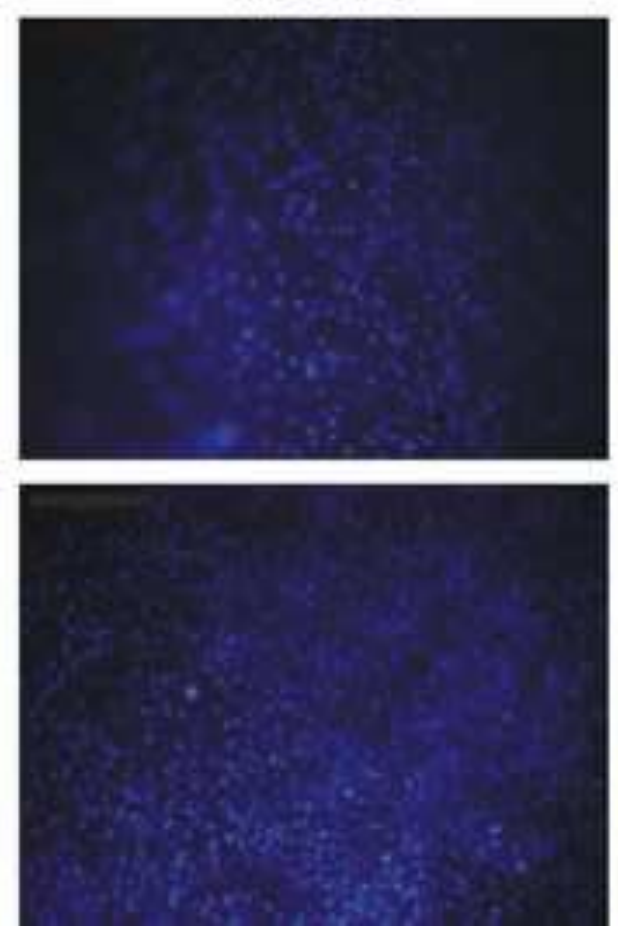

w/ SAPS
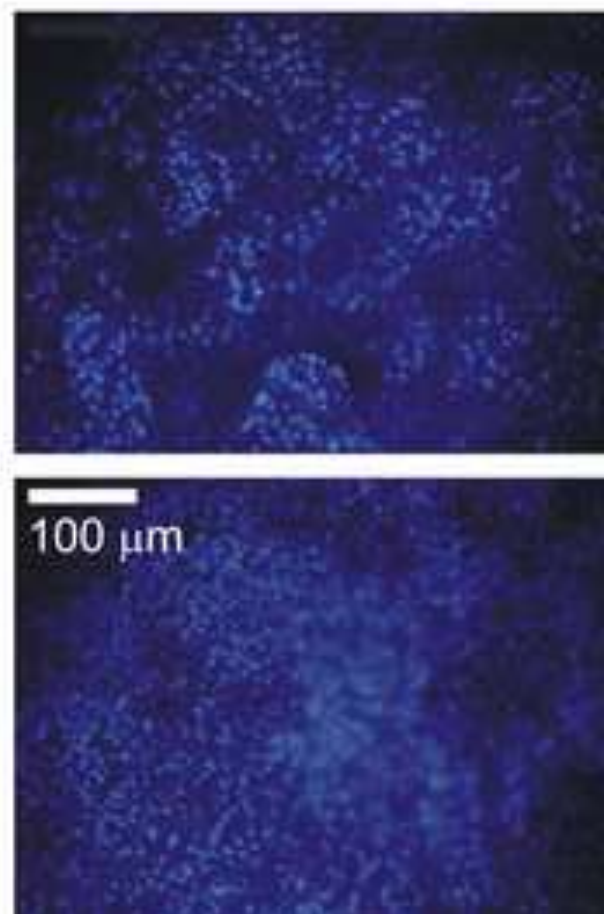


\section{Figure}

Click here to download high resolution image

\section{w/o SAPs}
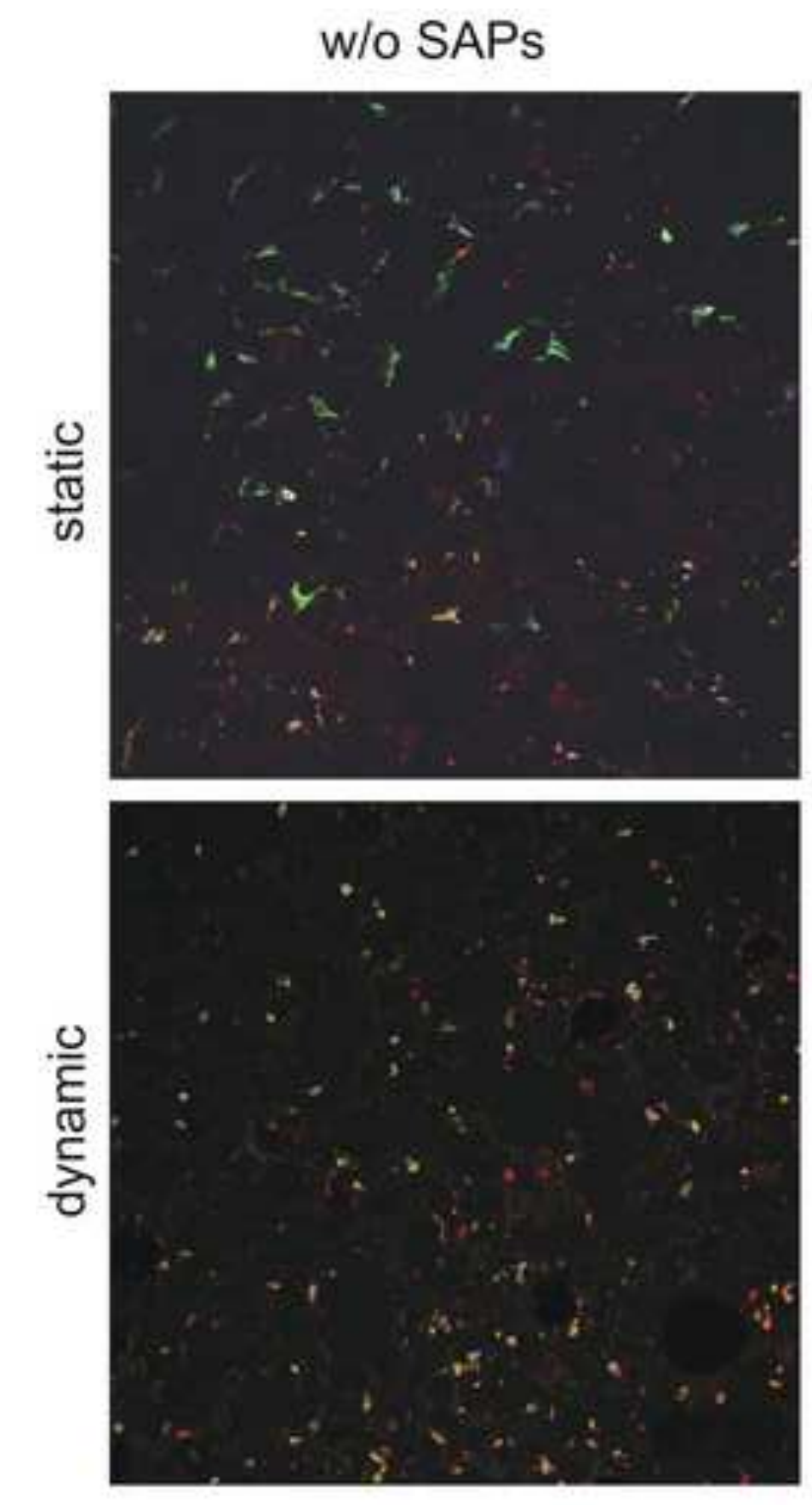

w/ SAPs
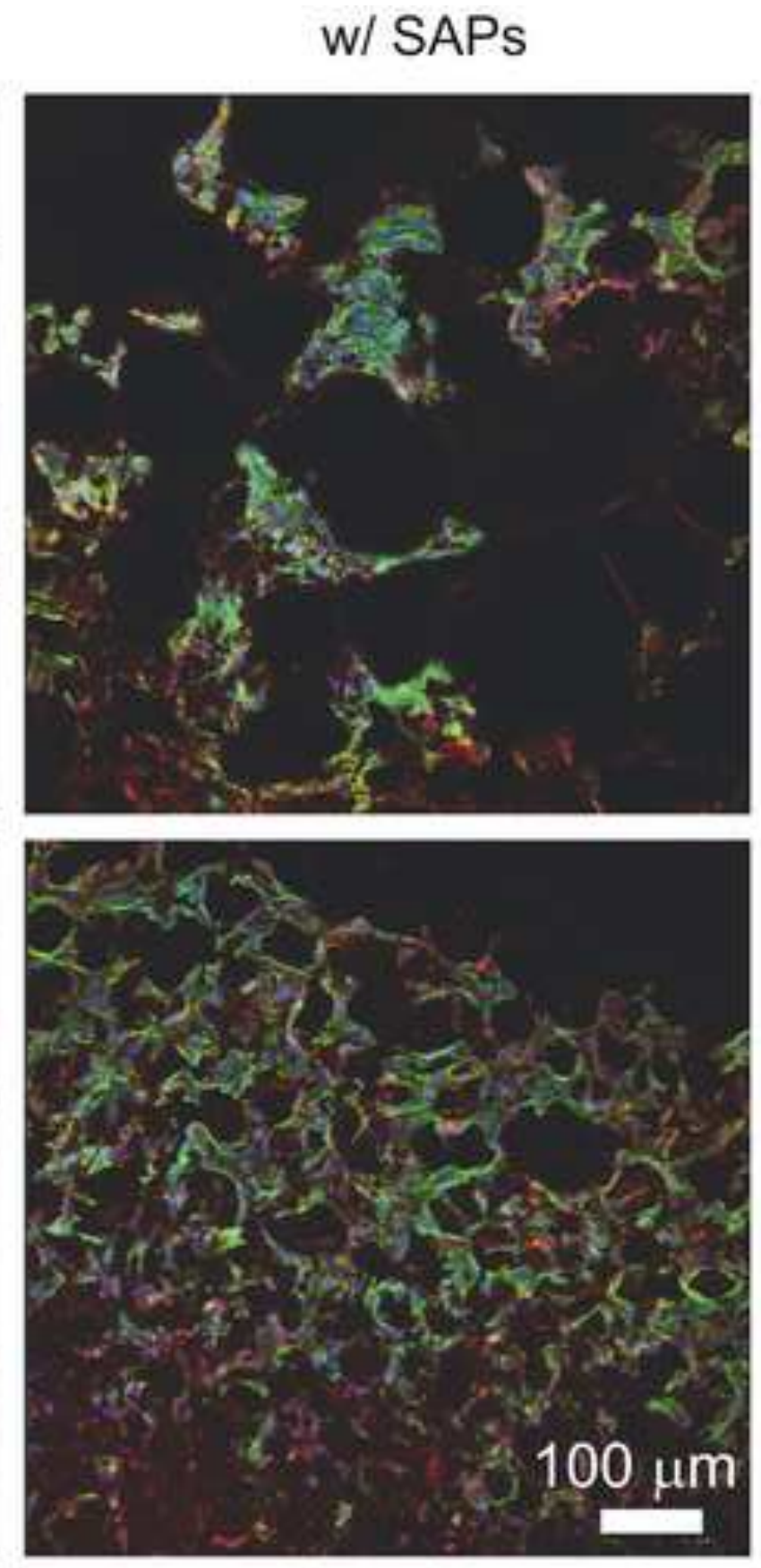
Click here to download high resolution image

1 day

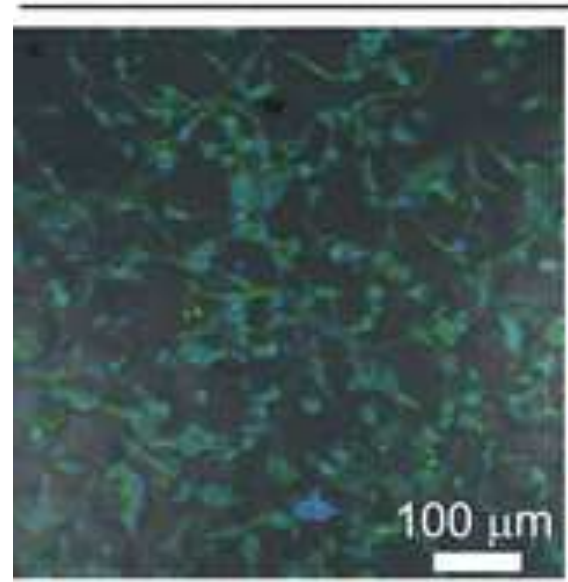

7 days

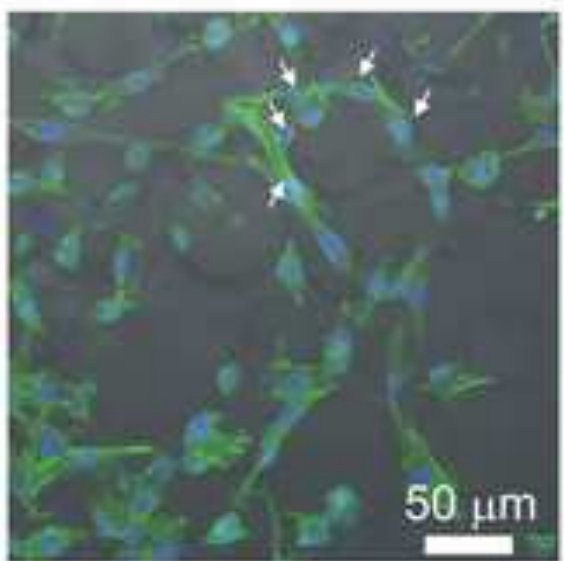

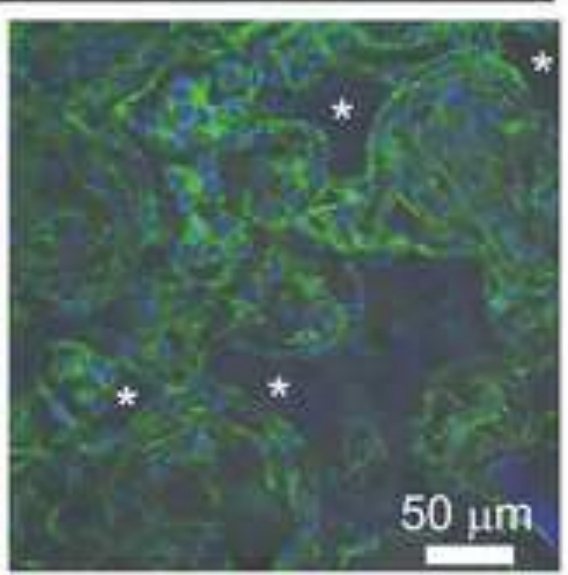


Click here to download high resolution image
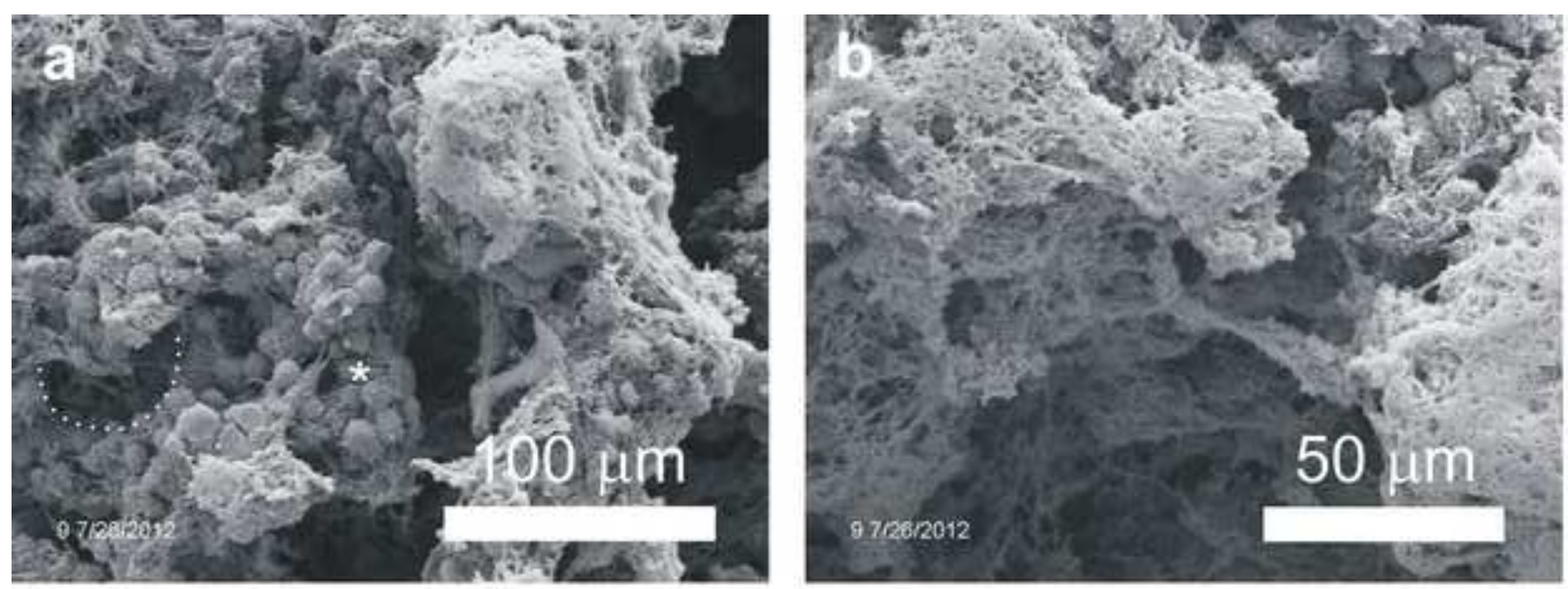
Click here to download high resolution image
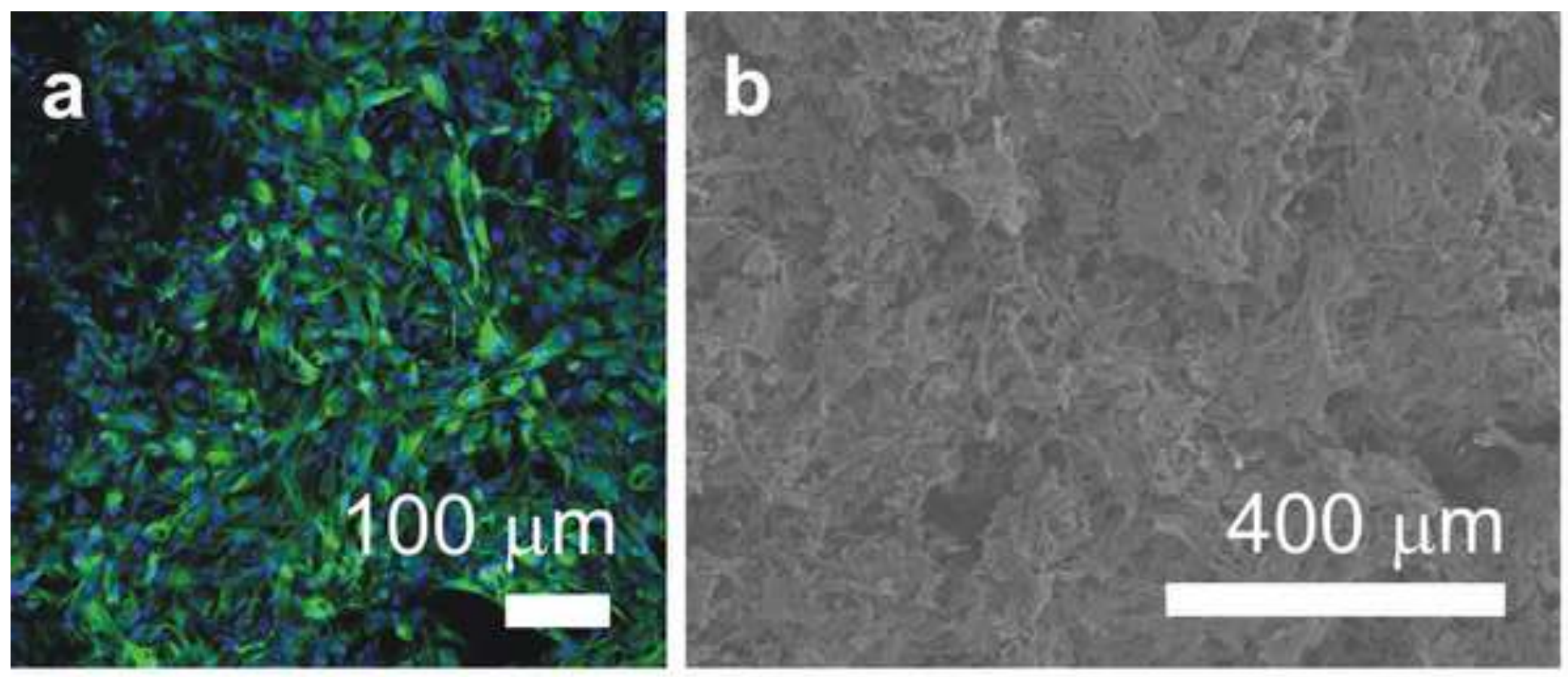

. 